\title{
Variable Market Exclusivity Periods for Pharmaceuticals
}

Michael Hsu $^{1}$, Ali Thaver ${ }^{2}$ and Gerard Anderson ${ }^{3^{*}}$

${ }^{1}$ Johns Hopkins School of Medicine, Baltimore, Maryland, USA

${ }^{2}$ Department of Medicine, Johns Hopkins Bayview Medical Center, Baltimore, Maryland, USA

${ }^{3}$ Department of Health Policy and Management, Bloomberg School of Public Health, Baltimore, Maryland, USA

"Corresponding author: Gerard Anderson, Department of Health Policy and Management, Bloomberg School of Public Health, Baltimore, Maryland, USA, Tel: 410-955-3241; E-mail: ganderson@jhu.edu

Received date: March 04, 2016; Accepted date: March 15, 2016; Published date: March 22, 2016

Copyright: ( 2016 Hsu M, et al. This is an open-access article distributed under the terms of the Creative Commons Attribution License, which permits unrestricted use, distribution, and reproduction in any medium, provided the original author and source are credited.

\begin{abstract}
Pharmaceutical companies are given a market exclusivity period that does not vary based on the level of research and development (R\&D) or the profits earned. The main purpose of this period is to protect the intellectual capital invested in a product allowing the inventor sufficient time to recoup the R\&D costs and to be able to earn a profit. Currently, only 2 in 10 marketed drugs are profitable and drug companies earn substantial profits on only a few blockbuster drugs. As a result, there are many neglected diseases and drug companies charge very high prices for these few profitable drugs. These high prices can restrict access; for example, less than $10 \%$ of people with hepatitis $C$ receive the appropriate drug primarily because of its high cost. A variable length market exclusivity period that takes into account a drug's R\&D cost (including the cost of all related products) and profits would provide greater incentives to invest in total R\&D, R\&D for a wider range of diseases and result in lower prices for expensive specialty drugs leading to greater access.
\end{abstract}

Keywords: Specialty drugs; Drug prices; Variable length patent

\section{Policy Points}

1. The current market exclusivity period structure results in a few very profitable drugs and many unprofitable drugs and underinvestment in neglected diseases.

2. Because of high drug prices, many people in the US do not have access to drugs that will cure a disease.

3. Market exclusivity lengths should be variable based on drugspecific R\&D spending and profit.

4. Implementing variable length market exclusivity periods would improve access to specialty drugs while encouraging pharmaceutical innovation and reducing spending on marketing.

\section{Variable Length Market Exclusivity Periods for Pharmaceuticals}

The Hatch Waxman Act was passed in 1984 with the dual purpose of improving access to drugs while also encouraging pharmaceutical innovation [1]. To address the former, the provision established the generic drug market through the development of the Abbreviated New Drug Application (ANDA) process that required a generic company simply to prove bioequivalence and not clinical efficacy or safety in order to manufacture and market an off-patent drug. At the same time, the Patent Term Restoration Act was implemented to encourage pharmaceutical innovation through extending the patent life by taking into account the time the company spent conducting lengthy clinical trials. Among other provisions the Hatch Waxman Act also provided a new drug product market exclusivity of 5 years for New Chemical Entities (NCEs), which by definition are innovative or have significant changes from a pre-existing drug.
Other changes have been made to the market exclusivity period in response to industry needs. The Orphan Drug Act was passed in 1983 to address the concern that drug companies were not investing pharmaceutical research in rare diseases with small patient populations. The policy guaranteed at least seven years market exclusivity for these types of treatments and turned out to be successful in incentivizing research into rare disease treatments [2]. In 1997, Congress enacted a new provision as part of the FDA Modernization Act that encouraged pharmaceutical studies targeting paediatric patients. Treatments undergoing such studies were given an additional 3 years exclusivity period. The Affordable Care Act passed in 2010 extended the exclusivity period of biologics in response to challenges companies faced in developing biologic treatments.

Today, the health care industry faces some historic challenges that may require another provision to the exclusivity period. One such challenge is the rising prices of specialty drugs that have led to restricted access and rationing for these high priced drugs. Gilead's Sovaldi is an example of a "breakthrough" curative drug for Hepatitis C whose high price tag is restricting access. The drug is able to cure people with hepatitis $C$ at very high rates $[3,4]$. The best available evidence suggests that the $\mathrm{R} \& \mathrm{D}$ expenses incurred originally by Pharmasset and later Gilead to get the drug through phase 3 clinical trials were around $\$ 300$ million, although a more accurate $R \& D$ cost estimating methodology is needed [5]. This cost may include some of the cost of the research funded by the NIH and does not reflect the cost of researching drugs by Pharmasset that were unsuccessful. The cost of manufacturing Sovaldi is relatively low - with estimates being $\$ 68$ $\$ 136$ for a 12 week course of treatment [6]. The retail price is $\$ 84,000$, although many insurers and hospitals receive discounts. In 2014, Sovaldi generated $\$ 10.3$ billion in revenues for Gilead pharmaceuticals and the patent will not expire until 2029 providing the company the possibility of earning considerable profits for the next 14 years [7]. 
Page 2 of 5

A concern about the high prices for specialty drugs such as Sovaldi is that access is being compromised and relatively few people with Hepatitis C are actually getting these new drugs. In May 2015, a Gilead spokesperson reported that 210,000 patients thus far had received treatment for Hepatitis C, representing less than $10 \%$ of the U.S with hepatitis $C$ [8]. Sovaldi and several other very expensive drugs are effective at curing Hepatitis $\mathrm{C}$ and if it were not for the high price many more patients with Hepatitis $\mathrm{C}$ would be taking the drug. A Senate Finance Committee investigation into the pricing of Sovaldi published in December 2015 revealed that access was not a consideration when Gilead priced their Hepatitis C drugs; in fact they priced the drug at a level that they knew would not maximize access [9].

Budget constraints have forced some state Medicaid programs and the Department of Veterans Affairs to provide the drug to only the sickest patients, thereby limiting access for many public beneficiaries who would benefit $[10,11]$. The Senate Finance Committee report revealed that Medicaid program spent $\$ 1$ billion on hepatitis $\mathrm{C}$ drugs in 2014 , but was able to treat only $2.4 \%$ of the approximately 700,000 Medicaid beneficiaries with Hepatitis C [9]. Many State Medicaid programs have been forced to ration care to remain within budget constraints. This may change as CMS has recently released guidance to the state Medicaid agencies suggesting that the restrictions they have imposed are inappropriate [12]. As a result, the state Medicaid programs may need to dramatically increase drug spending. Congress has recently increased the VA drug budget to allow more Veterans to obtain the hepatitis $\mathrm{C}$ drugs. The concern is that by requiring the VA and Medicaid to expand coverage it reduces the bargaining power of public programs with the drug companies. If the public programs have to provide the drug and the drug has a patent then all of the bargaining power is held by the drug company. A different approach is needed to ensure access for public beneficiaries at a reasonable price.

Privately insured patients, including Medicare beneficiaries, have a different access problem. Private insurers have placed specialty drugs on a high cost-sharing tier making it difficult for many patients to afford the drug. The Medicare program, for example, allows specialty drugs to be placed on high cost sharing tiers by the pharmaceutical drug plans established in the 2003 Medicare Modernization Act. When the drug is placed on a high cost-sharing tier, the Medicare beneficiary may be asked to pay $25 \%$ to $33 \%$ of the cost of the drug [13]. For drugs that cost nearly $\$ 100,000$, cost sharing seems to be effectively preventing many privately insured and Medicare beneficiaries from being cured of Hepatitis C. In the case of Medicare, out of pocket expenditures are capped although the beneficiary is still responsible for 5 percent of the cost after the out of pocket maximum is reached. Because of the high cost of hepatitis $C$ drugs, for example, $60 \%$ of the out of pocket payments occur after the out of pocket limit is reached because the beneficiary is still liable for 5 percent of the cost after the out of pocket limit is reached [13]. The out-of-pocket cost to the Medicare beneficiary can exceed $25 \%$ of their annual income if they rely solely on social security. Some privately insured benefit packages have out of pocket maximums, while others do not.

In addition to access, society's ability to afford these drugs remains a concern. Medicaid, the VA and DOD require supplemental appropriations to cover these drugs. The Medicare program recently discovered that spending for hepatitis $\mathrm{C}$ drugs increased from $\$ 300$ million to $\$ 9$ billion over the last two years [14]. The Hepatitis $C$ drugs are not the only specialty drugs on the market with a high price that could potentially limit access. A study estimated that spending on the new PCSK9 inhibitor class of cholesterol lowering drugs could increase the average health insurance premiums by $\$ 124$ per person per year [15]. 11 of 12 cancer drugs approved by the FDA in 2012 boasted a price of more than $\$ 100,000$ per year [16]. (Table 1) below shows a list of the most expensive specialty drugs in 2013 on an annual, per U.S. patient basis.

\begin{tabular}{|l|l|l|l|}
\hline & Drug Brand Name & Indication(s) & $\begin{array}{l}\text { Annual Cost per } \\
\text { US Patient }\end{array}$ \\
\hline 1 & Soliris & $\begin{array}{l}\text { Paroxysmalnocturnal } \\
\text { hemoglobinuria and atypical } \\
\text { hemolytic uremic syndrome }\end{array}$ & $\$ 536,629$ \\
\hline 2 & Naglazyme & $\begin{array}{l}\text { Mucopolysaccharidosis type } \\
\text { VI }\end{array}$ & $\$ 485,747$ \\
\hline 3 & Kalydeco & Cystic fibrosis & $\$ 299,592$ \\
\hline 4 & Cinryze & Hereditary angioedema & $\$ 230,826$ \\
\hline 5 & Questcor/Mallinckrodt & $\begin{array}{l}\text { Multiple sclerosis, infantile } \\
\text { spasms }\end{array}$ & $\$ 205,681$ \\
\hline 6 & Sprycel & Chronic myeloid leukemia & $\$ 149,762$ \\
\hline 7 & Pomalyst & Multiple myeloma & $\$ 147,302$ \\
\hline 8 & Xyrem & Narcolepsy & $\$ 143,604$ \\
\hline 9 & Erbitux & Colon cancer & $\$ 137,953$ \\
\hline 10 & Revlimid & Multiple myeloma & $\$ 128,666$ \\
\hline
\end{tabular}

Table 1: Top 10 specialty drugs by annual cost per U.S. patient in 2013 (Source: FiercePharma based on EvaluatePharma ${ }^{\oplus}$ analysis [17]).

While some of these specialty drugs may be cost effective and add value in the long run, their high prices is a major contributing factor to the 12.2 percent increase in U.S. drug spending in 2014 [15].

Policymakers have begun to respond to rising drug spending. There are a number of proposals developed by academics and researchers [18-20].Congress is holding hearings on drug spending (VA, Senate Aging, and Government Operations). The topic of drug spending has been part of the presidential debates. Hillary Clinton has proposed to shorten market exclusivity for biologics from 12 years to 7 years and is proposing that Medicare be permitted to directly negotiate with pharmaceutical companies. Legislators in California, Oregon, and New York are promoting legislation to increase price transparency among pharmaceutical companies by requiring them to report their development, manufacturing and marketing costs [21].

The need to reconsider the exclusivity period is highlighted not only by the high prices of new specialty drugs that limit access but also because of the increasing need to encourage pharmaceutical innovation. 2015 Profile: Pharmaceutical Research Industry. Rep. PhRMA, Apr. 2015. Web 20 Feb 2016 when the R\&D expenditures are taken into account [3]. An article suggests that return on innovation is declining and that many drugs are unable to recoup their research and development (R\&D) and other costs for certain drugs [22]. Therefore drug companies must earn profits on the few successful drugs to cover the costs of the R\&D and the less profitable drugs. This economic model results in much higher drug prices for a few "blockbuster" drugs. 
The aforementioned concerns have already caused some debate in the proper length of pharmaceutical market exclusivity. The National Academics Committee on Science, Engineering, and Public Policy as well as the pharmaceutical company GlaxoSmithKline have proposed extensions of the exclusivity period for pharmaceutical drugs in line with biologics under the ACA $[23,24]$. On the other hand, democratic representatives Jan Schakowsky (D-IL) and Rosa DeLauro (D-CT) support shortening the exclusivity period for biologics due to concerns around high prices and limited access to treatments.

The current challenge is that adjustments made to the exclusivity period must balance the need for innovation and access to medicines two essential goals of drug policy. The existing patent period and market exclusivity length seems to have fostered a "boom or bust" approach that may not be the most conducive to promoting R\&D and ensuring access to essential pharmaceuticals. There are people that cannot afford drugs that will cure their disease and many neglected diseases do not generate the possibility of substantial profits to warrant drug company investments. A variable length exclusivity period could address both of these concerns.

\section{Variable Length Market Exclusivity Periods}

One modification to the market exclusivity period that could simultaneously spur innovation and improve access is to create an adjustable market exclusivity period that is drug-specific. The two most important factors that would determine the exclusivity period would be $R \& D$ expenditures and profits on that drug, but there could be additional adjustments for therapeutic benefit, degree of innovation and the nature of the disease.

The simplest mechanism is to base the exclusivity period on the level of R\&D investment and the profits earned on that drug and the company would be able to earn a multiple of the R\&D investment before the patent expired. This would allow a greater percentage of drugs to become profitable, but would limit the profits on a few drugs. Under this option, a company could earn a profit on the drug even if it spent a considerable amount on R\&D because the exclusivity period would be longer. However, if the company set the price very high and earned considerable profits at the beginning, then the patent life would be shorter. The objective is to allow the drug company to earn a reasonable rate of return on its $\mathrm{R} \& \mathrm{D}$ investment. The Federal government is already granting the drug company a time limited monopoly by giving them a patent; the relevant question becomes whether the market exclusivity period should vary based on the particular circumstances for that drug.

For this proposal to become operational, it would be necessary to determine the R\&D investment associated with the specific drug and the profits earned by that drug. The drug company would need to provide information to the federal government allocating R\&D costs for that specific drug and all related R\&D on unsuccessful drugs. There would need to be a methodology to determine related R\&D expenses and the ability to audit them. This is already happening, as some states are requiring the drug companies to report their $\mathrm{R} \& \mathrm{D}$ investments. It would be easier for drug companies to have one federal form than potentially 50 different state forms.

Research and development costs would be for actual R\&D expenditures and would not account for acquisition costs incurred if one company purchases another company's drug. In the case of Sovaldi, for example, the cost of R\&D would be the estimated $\$ 300$ million and not the $\$ 11$ billion that Gilead spent to acquire the drug.
By basing the amount on the actual R\&D, the proposed option would have the added benefit of not encouraging drug companies acquire drugs and then raise prices. The prices for Sovaldi are approximately double what they were forecast to be before the acquisition.

Profits for specific drugs would be calculated from financial reports. The main policy choice for Congress is to select the multiple of R\&D that encourages innovation while promoting responsible pricing and increased access. Existing law has chosen to apply a uniform multiple, and does not make allowances either for the level of R\&D investment or profits.

The main advantage of this approach is that it rewards investment in $\mathrm{R} \& \mathrm{D}$ by basing the market exclusivity period on the level of $\mathrm{R} \& \mathrm{D}$ investment. The $\mathrm{R} \& \mathrm{D}$ multiple should be set such that most drugs' exclusivity periods will be lengthened and a few high priced specialty drugs will have shortened exclusivity periods. The result is that pharmaceutical companies will be able to earn profits on a greater percentage of drugs. A study conducted in 2011 shows that lengthening the exclusivity period for conventional drugs will increase pharmaceutical revenues and encourage innovation [25]. Investment in neglected diseases will also increase. At the same time, the exclusivity period of a few very expensive drugs would be shortened and they would enter the generic market faster improving access to these drugs. It would also encourage them to select a lower price that would improve access in order to have the market exclusivity period last longer.

The variable exclusivity length will encourage pharmaceutical companies to invest in more $\mathrm{R} \& \mathrm{D}$ because the exclusivity period is directly associated with the level of $R \& D$ investment. It would encourage greater investment in truly innovative drugs since they are generally more expensive to develop than "me too" drugs. By basing the market exclusivity length on the level of R\&D investment, there is the concern that companies would over invest in $\mathrm{R} \& \mathrm{D}$, but if they did this then they would be less likely to earn a profit on the drug. Currently the large drug companies invest twice as much on marketing as on $\mathrm{R} \& \mathrm{D}$. This proposal would change the incentives to invest more in $\mathrm{R} \& \mathrm{D}$ and less in marketing for the few blockbuster drugs since additional sales at very high prices would shorten the market exclusivity.

One potential concern is that companies that are more efficient at conducting $\mathrm{R} \& \mathrm{D}$ would have lower $\mathrm{R} \& \mathrm{D}$ expenditures and therefore have shorter market exclusivity. This could be remedied by a number of modifications such as a minimum period of market exclusivity. There would still be an economic incentive to conduct the R\&D as efficiently as possible since the profitability of any product is always in doubt since a competitor might develop a new drug that would impact sales.

Access will improve under the proposed mechanism. It is common for drug companies to set a high price for innovative drugs initially and then gradually lower the sales price. In economics, this is known as price skimming [26] and is used primarily so that the company can get as much of the consumer surplus as possible. The people who are able to pay a high price initially will be able to acquire the drug first and then the drug company gradually lowers the price to get the additional patients that are only able to pay the lower price. This means that some people have to wait a long time to obtain access to these drugs. This seems to be what is happening with hepatitis $C$ drugs and many other specialty drugs. Under the proposed variable market exclusivity option, companies will have to decide between setting a higher price initially 
and obtaining a shorter exclusivity period, or setting a lower price and thus obtaining an extended exclusivity period.

\section{Limitations and Considerations}

One practical concern is that generic companies would need to know exactly when a drug would lose market exclusivity so that they can file applications with the FDA. To address this problem, the mechanism could adopt discrete exclusivity periods instead of continuous ones. Based on the R\&D cost and the anticipated profits the drug would initially be given a discrete time period (assume 7 years). If the profits in the first 4 years were greater than projected, then the time period could be reduced (e.g. 6 years) and if the profits were less than projected then the time period could be increased (e.g. 10 years). This would provide sufficient warning for generic companies to submit the ANDA applications to sell the generics when the market exclusivity terminates.

A central issue in implementing this proposed policy is its complexity. It will take a new reporting system to determine the level of $\mathrm{R} \& \mathrm{D}$ investment for a specific drug. As mentioned earlier, some states are already mandating pharmaceutical company transparency by requiring them to report their $R \& D$ investments. This creates additional administrative burden since each state has a different form. Because the market exclusivity period is already being granted by the Department of Health and Human Services (DHHS), DHHS would need to create a mechanism to determine the level of R\&D investment and the profits for specific drugs for this proposal to be operational. It will be necessary for drug companies to identify profits for specific drugs and this could require additional financial accounting.

Countries like the UK already have similar regulatory guidelines in place to help curb high specialty drug prices. Under the Pharmaceutical Price Regulation Scheme (PPRS), the government negotiates a profit limit with drug companies. If at the five-year mark drug profits surpass negotiated limits, companies have to pay back the government a certain portion of the exceeding profit.

\section{Possible Refinements}

Some drugs confer greater therapeutic benefits than others. A possible revision would be to adjust the exclusivity time period based on a measurement of its therapeutic benefit such that curative drugs or drugs with a higher incremental cost-effectiveness ratio (ICER) would be given a longer exclusivity period.

It would be possible to adjust the time period to reward drugs that treat certain medical conditions with greater public concern. The National Institute for Clinical Effectiveness (NICE) in the United Kingdom has modified its criterion on several occasions to give special consideration to certain diseases (most commonly certain types of cancer). An analysis done in 1999 showed that the National Institutes of Health provided additional funding for AIDS and breast cancer compared to other diseases [27]. Congress could adjust the market exclusivity period for certain medical conditions, although this could become very political.

\section{Conclusion}

One may claim that variable market exclusivity hinders free market dynamics. However, the government is already granting the drug company a time limited monopoly to sell the drug, so there is already interference in the marketplace. Because there is already market interference, the more pertinent question is simply whether there should be a fixed exclusivity period or allow the exclusivity period to vary based on the level of $\mathrm{R} \& \mathrm{D}$ investment in the drug and the profits earned. The potential benefits of varying the market exclusivity are greater investments in $\mathrm{R} \& \mathrm{D}$, increased investment in neglected diseases, and greater access to pharmaceuticals.

\section{References}

1. Troy D (2003) Drug Price Competitition and Patent Term Restoraction Act of 1984. U S Food and Drug Administration.

2. Lichtenberg FR, Waldfogel J (2016) Does Misery Love Company? Evidence from pharmaceutical markets before and after the Orphan Drug Act. National Bureau of Economic Research.

3. Afdhal N, Zeuzem S, Kwo P, Chojkier M, Gitlin N, et al. (2014) Ledipasvir and sofosbuvir for untreated HCV genotype 1 infection. N Engl J Med 370: 1889-1898.

4. Zeuzem S, Dusheiko GM, Salupere R, Mangia A, Flisiak R, et al. (2014) Sofosbuvir and ribavirin in HCV genotypes 2 and 3. N Engl J Med 370: 1993-2001.

5. Sachs J (2015) The Drug That Is Bankrupting America. The Huffington Post.

6. Hill A, Khoo S, Fortunak J, Simmons B, Ford N (2014) Minimum Costs for Producing Hepatitis C Direct-Acting Antivirals for Use in Large-Scale Treatment Access Programs in Developing Countries. Clin Infect Dis.

7. Harrison C (2013) Patent battle lines drawn as sofosbuvir gains approval. Nat Rev Drug Discov.

8. Chen C, Cortez MF (2015) Gilead's Gaffe Leads Drugmakers to Pledge More Openness on Price.

9. Hatch OG, Wyden R (2015) The Price of Sovaldi and the its impact on the U.S. Health Care System.

10. http://www.cbsnews.com/news/hepatitis-c-cure-veterans-affairscongressional-hearing-cbs-news-investigation/

11. Harper J (2015) States Deny Pricey Hepatitis C Drugs to Most Medicaid Patients. NPR.

12. DeBoy A (2015) Assuring State Medicaid Beneficiaries Access to Hepatits C (HCV) Drugs. Department of Health and Human Services.

13. http://kff.org/report-section/it-pays-to-shop-variation-in-out-of-pocketcosts-for-medicare-part-d-enrollees-in-2016-findings/.

14. http://www.usnews.com/news/business/articles/2015/11/13/ apnewsbreak-medicare-spending-9b-on-hepatitis-c-drugs.

15. Schulman KA, Balu S, Reed SD (2015) Specialty Pharmaceuticals for Hyperlipidemia Impact on Insurance Premiums. N Engl J Med 373: 1591-1593.

16. Kantarjian H (2013) The Price of Drugs for Chronic Myeloid Leukemia (CML); A Reflection of the Unsustainable Prices of Cancer Drugs: From the Perspective of a Large Group of CML Experts.

17. Palmer E (2014) The top 10 most expensive drugs of 2013. FiercePharma.

18. Lee JLY, Fischer MA, Shrank WH, Polinski JM, Choudhry NK (2012) A systematic review of reference pricing: implications for US prescription drug spending. Am J Manag Care 18: e429-437.

19. Wilensky GR (2015) IMproving and refining the affordable care act. JAMA 314: 339-340.

20. Kanavos P, Ferrario A, Vandoros S, Anderson GF (2013) Higher US Branded Drug Prices And Spending Compared To Other Countries May Stem Partly From Quick Uptake Of New Drugs. Health Aff (Millwood) 32: 753-761.

21. Pollack A (2015) Drug Prices Soar, Prompting Calls for Justification. The New York Times.

22. Berndt ER, Nass D, Kleinrock M, Aitken M (2015) Decline In Economic Returns From New Drugs Raises Questions About Sustaining Innovations. Health Aff (Millwood) 34: 245-252.

23. National Academies Press (2007) Rising Above the Gathering Storm: Energizing and Employing America for a Brighter Economic Future. 
Citation: Hsu M, Thaver A, Anderson G (2016) Variable Market Exclusivity Periods for Pharmaceuticals. Health Econ Outcome Res Open Access 2: 111. DOI: 10.4172/2471-268X.1000111

Page 5 of 5

24. So AD, Katz SL (2010) Biologics Boondoggle. The New York Times.

25. Goldman DP, Lakdawalla DN, Malkin JD, Romley J, Philipson T (2011) The Benefits From Giving Makers Of Conventional 'Small Molecule' Drugs Longer Exclusivity Over Clinical Trial Data. Health Aff Proj Hope 30: 84-90.
26. Lu ZJ, Comanor WS (1998) Strategic Pricing of New Pharmaceuticals. Rev Econ Stat 80: 108-118.

27. Gross CP, Anderson GF, Powe NR (1999) The Relation between Funding by the National Institutes of Health and the Burden of Disease. N Engl J Med 340: 1881-1887. 